University of Miami/Miller School of Medicine

Fielding Graduate University

*Corresponding Author : Tiffany Field, PhD, 2889 McFarlane Rd. Miami, Florida 33133, USA, Tel: -305-975-5029;

E-mail: tfield@med.miami.edu

Received date: May 11, 2019; Accepted date : June 03, 2019; Published date: June 10, 2019

Citation : Field T(2019), Adolescent Internet Gaming Disorder: ANarrative Review. Addict Res AdolBehav2(1).Doi:10.31579/JARAB.2019/005.

Copyright : (C2019 Field T. This is an open-access article distributed under the terms of The Creative Commons Attribution License, which permits unrestricted use, distribution, and reproduction in any medium, provided the original author and source are credited.

\title{
Abstract
}

This narrative reviewis based on aliterature search on PsycINFO and PubMed that involved entering theterms adolescentinternet gaming for papers published during the last five years. Following exclusion criteria, 72 papers could be classified as internet gaming or internet gaming disorder/addiction studies including research on the prevalence, effects/comorbidities, risk factors and interventions for those problems. The prevalence of both internet gaming and internet gaming disorder has varied by culture. The effects/comorbidities have included hyperactivity, inattentiveness, cyberbullying, depression, anxiety and substance use. The risk factor studies have focused on impulsivity, sensation-seeking, and aggressivity. Altered autonomic and central nervous system function have also been notable including decreased heart rate variability and fMRI data showing less activation of the prefrontal cortex, ventral striatum and amygdala (areas that are involved in modulating impulsivity, rewardseeking and aggression respectively) as well as reduced gray and white matter. Surprisingly, given the prevalence and severity of internet gaming disorder, very little prevention/intervention research appears in this recent literature. Research is also missing on peer relationships/rejection as potential risk factors. Like other literature on adolescent problems, this research is limited by primarily deriving from self-report and parent report and by the absence of longitudinal data that might inform whether the behavioral and brain data being reported are effects of or risk factors for internet gaming addiction.

\section{Adolescent Internet Gaming Disorder: A Narrative Review}

This narrative review is based on a literature search on PsycINFO and PubMed that involved entering the terms adolescent internet gaming for papers published during the last five years. Following exclusion criteria (case studies and non-English papers), 72 papers could be classified as internet gaming or internet gaming disorder/addiction including research on the prevalence, effects/comorbidities, risk factors and interventions. The prevalence of both internet gaming and internet gaming disorder has varied by culture. The effects/comorbidities have included hyperactivity, inattentiveness, cyberbullying, depression, anxiety and substance use. The risk factor studies have focused on impulsivity, sensation-seeking, and aggressivity. Altered autonomic and central nervous system function have also been notable including decreased heart rate variability and fMRI data showing less activation of the prefrontal cortex, ventral striatum and amygdala (areas that are involved in modulating impulsivity, reward-seeking and aggression respectively) as well as reduced gray and white matter.

Surprisingly, given the prevalence and severity of internet gaming disorder, very little prevention/intervention research appears in this recent literature. Research is also missing on peer relationships/rejection as potential risk factors. Like other literature on adolescent problems, this research is limited by primarily deriving from self-report and parent report and by the absence of longitudinal data that might inform whether the behavioral and brain data being reported are effects of or risk factors for internet gaming addiction. Accordingly, these topics are discussed in the following sections.

\section{Prevalence of Internet Gaming}

\section{The Nature of the Prevalent Games}

A videogame developer has provided interesting insights on the different types of Internet games that have become increasingly popular including power games, making-choice games, incremental games and online role-playing games [1]. He has described power games as similar to the power game called Oasis that was featured in Spielberg's 2018 movie called "Ready Player One".

Auctores Publishing - Volume2-006 www.auctoresonline.org Page-01
Others he identified as power games include Final Fantasy, World of Warcraft, Diablo, Sky Room and the game he is designing called Destiny. In these games, he suggests that the driving purpose is to achieve higher levels and greater numbers, much as in pursuing power. Other games he described are for "making choices" and "mastering the mechanics of the game" including The Walking Dead series and Over watch. The third type of game he described is called incremental games in which the player does not have to interact with the game but simply observes. These include games like Titans, Quicker Heroes and Idol Heroes. Finally, the online role-playing games involve repetitive activity again designed to increase one's power. Examples he gave are World of Warcraft, Ever Quest, Dark Agent, and Ultimo Online. Given Irby's graduate studies on Sri Lankan Buddhism and Hinduism, it's interesting that he analogizes these online games to the severe meditative practices of Buddhist and Hindu ascetics who reputedly engaged in the severe meditation to achieve power [1]. This author who continues to develop these games may not realize how prevalent and addictive gaming has become, although he mentioned the chemical dependency that derives from the brain's reward system releasing dopamine as individual's progress through the videogames [1].

In addition to chemical dependency, the thousands of hours of playtime that are required to make progress in these games have been associated with excessive sedentary activity. In a recent study in the Journal of the American Medical Association, the number of sitting hours for adolescents has significantly increased from an average of 7 to 8.2 over the last 10 years [2]. In addition, the percentage of adolescents who spend at least one hour a day outside of school time using the computer has doubled over the last decade from 30 to $62 \%$. This is considered problematic given that sedentary behavior has increased the risk for diabetes, heart disease, some cancers and even early mortality [2].

\section{The Prevalence of Internet Gaming in Different Cultures/Countries}

The prevalence of Internet gaming has varied widely across different cultures/countries. In the Youth Risk Behavior Survey of 15,624 US high school students, $19 \%$ of the adolescents spent five or more hours daily on video gaming [3]. A greater percentage of female adolescents than male 
adolescents reported spending no time or five or more hours on gaming ( $21 \%$ for female vs. $18 \%$ for male adolescents). 
For female adolescents, a greater prevalence of mental problems was associated with increased time spent whereas a J-shaped curve for the male adolescents suggested an initial decrease followed by a slow increase and then a rapid increase beginning at four hours or more. Spending no time or five hours or more daily in video gaming was associated with increased mental problems for both sexes. Spending one hour or less was associated with fewer depressive symptoms and suicidal behavior when compared with no use or excessive use. In another large sample study ( $\mathrm{N}=5045), 56 \%$ of the students were gamers based on the 12-item Problematic Online Gaming Questionnaire [4]. Latent profile analysis revealed that $5 \%$ of the adolescents belonged to a high risk group and $13 \%$ to a low risk group.

A higher incidence of gaming (80\%) has been reported for Saudi Arabia students based again on a self-report questionnaire [5]. These students reported that the most important motivator for gaming was fun and excitement, followed by getting rid of boredom. The drawbacks noted were interference with sleep time, physical activity and real-life. Although the students' basal metabolic index was not associated with gaming, academic performance was lower and the prevalence of smoking, road traffic accidents and violence was especially noted among those who preferred racing games and those gaming in cyber cafés.

A similarly high prevalence of gaming has been noted in the Australian Child and Adolescent Survey of Mental Health and Well- being which involved the completion of questionnaires by 296711 - 17-year-olds $(85 \%)$ [6]. Once again, psychological distress and problem behavior were twice as prevalent for girls as for boys, and those with emotional problems spent the most time playing games. Although it is not possible to determine the direction of effects, multivariate analysis showed that problem behavior, attempting suicide, experiencing high levels of psychological distress, using alcohol and living in a poorly functioning family were associated with more gaming. An even higher incidence of gaming (94\%) was reported in a study on 503 Hong Kong adolescents [7]. These rates of gaming are extremely high and, fortunately, the more serious Internet Gaming Disorder/addiction is not as prevalent.

\section{Prevalence of Internet Gaming Disorder/Addiction}

Internet Gaming Disorder or Internet Gaming Addiction has been recently defined by the American Psychiatric Association as a diagnostic category, and its prevalence has been noted to range between $1 \%$ and $9 \%$ depending on the age of the student and the country of residence [8]. The APA has defined Internet gaming disorder as the persistent and recurrent use of the Internet to engage in games, often with other players, leading to a significant clinical impairment or distress. The online games such as massively multiplayer online roleplaying games, for example, have been noted to cause clinically significant impairment. For a diagnosis of Internet Gaming Disorder, five or more of nine criteria are met for the diagnosis including:1) preoccupation with games; 2) withdrawal symptoms when gaming is removed such as irritability, anxiety or sadness; 3 ) tolerance or the need to spend increasing amounts of time on games; 4) unsuccessful attempts to reduce participation in games;

5) loss of interest in real life relationships and other entertainment; 6) continued excessive use of games despite experiencing psychosocial problems; 7) deceiving family members about the amount of gaming; 8) using games to escape or relieve negative mood states; and 9) jeopardizing or losing a relationship, job, educational or career opportunity.

Following on the development of the criteria for Internet Gaming Disorder, researchers developed a structured clinical interview for Internet Gaming Disorder and a group of 236 adolescents from clinical settings were recruited to evaluate the psychometric properties of this interview [9]. The likelihood ratio estimates indicated that this was a reliable interview. Another instrument called the Gaming Addiction Identification Test has been developed using professional, parent and adolescent raters to determine content validity which ranged between .97 and .99 , although additional research is needed for determining construct validity and criterion-related validity [10].
In a recent systematic review of the literature on Internet Gaming Disorder, the prevalence in clinical samples averaged 2-6\% [11]. A slightly higher average prevalence at $5 \%$ has been noted in a recent meta- analysis on 16 studies [12]. In this sample, male adolescents reported a higher prevalence of $7 \%$ versus $1 \%$ for female adolescents.

Like other adolescent problems, for example, Internet addiction [13], cyberbullying [14], depression [15], suicidal ideation/attempts [16] and violence [17], Internet Gaming Disorder (IGD) has varied widely across cultures/countries. In a survey of seven European countries on a sample of 12,938 adolescents, $1.6 \%$ of adolescents met full criteria for Internet Gaming Disorder with another $5.1 \%$ being at risk by fulfilling up to four criteria [18]. Variation was noted across the participating countries. In a separate study on German adolescents, data from the Videogame Dependency Scale that covers all nine criteria of IGD revealed that $1.2 \%$ of adolescents could be classified by the DSM-V [19]. The IGD students played games for longer periods, skipped school more frequently, had lower grades, and reported more sleep problems and feelings of being addicted to gaming. The most frequently reported symptoms in this sample were escaping adverse moods, preoccupation with gaming, giving up other activities, tolerance and withdrawal.

A higher prevalence of problematic gaming (9\%) has been reported for five Parisian middle schools including 434 adolescents [20]. Of these, $78 \%$ were boys. The two types of games that were responsible for problematic use were role-playing games and first- person shooter games. Although the students reported that gaming affected their physical and mental health, they didn't think that gaming affected their academic performance. More negative consequences were reported by girls than boys including eating problems, sleep problems, vision problems, conflicts with parents, lots of wasted time and lack of school investment. They also listed risk factors including poor academic performance, lack of friends, and lack of selfconfidence and family problems. They viewed IGD as a failure to stop playing, playing instead of fulfilling one's obligations and doing nothing but gaming. In a similar age sample of 1071 eighth graders in Slovenia, the prevalence of IGD was $2.5 \%$ [21]. This lower incidence may relate to cultural differences or to simply using a different measure (the 9-item Internet Gaming Disorder Scale).

In still another middle-school sample, 2024 Korean students were assessed on the nine diagnostic criteria for Internet Gaming Disorder [22]. In this sample, $70 \%$ were gamers ( $51 \%$ boys) and $6 \%$ (10\% boys $1 \%$ girls) were classified as adolescents with Internet Gaming Disorder. The prevalent symptoms were mood modification, behavior problems, conflict, withdrawal and relapse in that order. Comorbid anxiety was noted in $9 \%$ of the students, depression in $15 \%$ and impulsive symptoms in $11 \%$ of the students. In a study from Taiwan, the prevalence of gaming disorder was half that of the Korean sample at 3\% [23]. But in Hong Kong, gaming was reported for as many as $94 \%$ of adolescents, and as many as $16 \%$ were identified as having Internet Gaming Addiction [7]. The risk for gaming addiction was significantly higher among boys as well as among those with poor academic performance and those who preferred playing multiplayer online games. Other risk factors were the average amount of time spent gaming per week, the frequency of spending money on gaming, perceived family disharmony and, surprisingly, having more close friends.

A couple variations of gaming appeared in this recent literature including a paper on social casino gaming and a few papers on active versus non- active gaming. In the study on casino gambling which offers the opportunity to gamble without monetary gains and losses, 12\% of the 10,035 Canadian students in grades 9 to 12 in this study reported having participated in social casino games [24]. Those players were more likely to participate in monetary gambling activities, more likely to be males, to have weekly spending money, to have friends and parents who gamble and to spend time on the Internet.

Active and non-active video gaming have been compared by a survey on 373 adolescents age 12-16 in a series of papers by the same group of researchers. In one of their papers, $3 \%$ were reported to play exclusively active games, $40 \%$ both active and non-active games, $1 \%$ exclusively non active games and $17 \%$ no game playing [25]. Active game playing averaged 1.5 days per school week for 36 minutes on average and one day per weekend for 42 minutes. 
In this review of 32 studies, poor mental health status was noted for Non-active game playing occurred on 3.3 days per school week for 65 minutes and 1.4 days per weekend for 80 minutes. Boys and older adolescents were more likely to play non active games than girls or younger adolescents [26]. In another paper by the same group, 24-hour recall diaries were completed electronically on five random weekdays and randomly assigned weekend days over a one-month period [27] Adolescents who played active video games also reported more time playing non-active video games, and playing active video games was associated with an increase in snack intake.

In a third paper, the authors reported that playing active games was comparable to light-to-moderate intensity physical activity [28]. According to the adolescents, active gaming replaced sedentary screen time such as TV viewing, Internet and non-active gaming. In still another paper by the same group, active gaming was associated with a more positive attitude toward active gaming, a less positive attitude toward non-active gaming, and having brothers/sisters and friends who spend more time on active gaming [29]. In a study by another research group, a sample of 45 Italian teenagers completed a questionnaire about their videogame behavior and were then divided into action videogame player versus non-action videogame player groups and were given cognitive tests [30]. The results were consistent with previous findings that those in the active group had greater performance for instantly enumerating items. However, that group had a decrease in performance over time typical of a sustained attention task compared with a nonactive group.

In one of the only longitudinal studies that could be found in this current literature, Swedish adolescents $(\mathrm{N}=1576)$ (who were $13-15$ years-old at time 1 of the study and at time 2 were 16-18 years-old) completed the Gaming Addiction Identification Test and the Problem Gambling Severity Index [31]. After adjusting for sex, age and ethnicity as well as the frequency of gambling activities and gambling time at baseline, problematic gaming was relatively stable over time. And, problematic gaming at time 1 increased the probability of having problem gaming three years later, highlighting the stability of problematic gaming.

Gender differences have also been noted for Internet Gaming Addiction. In many studies, both the prevalence of Internet gaming and problematic use has been greater for males versus females, as in other addictions including internet addiction itself [13]. In one study, for example, the prevalence of gaming was greater for boys $(60 \%)$ than for girls $(14 \%)$ and problematic gaming was also more prevalent among boys $(5 \%)$ than girls $(1 \%)$, a 5 to 1 male/female ratio for both gaming and game addiction [32] (Table 1).

\section{Effects of Internet Gaming Addiction}

Multiple effects which could also be called comorbidities have been noted for gaming addiction including the other addictions already mentioned. It is not clear whether these are in fact effects of Internet gaming addiction or risk factors given that most of the studies have been cross-sectional not longitudinal. Other comorbidities have included attention problems, hyperactivity and mental health problems including depression and anxiety, other addictions including cyberbullying and substance use as well as family conflict.

In a study based on the Videogame Addiction Test, high problematic game use was associated with lower self-reported school performance, negative self-esteem, loneliness, social anxiety and depressed mood [32]. High scores on the addiction test were also associated with greater nicotine, alcohol and cannabis use among boys, with the rate being twice that reported by girls. Similar findings were noted in a systematic review of six online databases from which 91 studies met inclusion criteria [33]. The review suggested that high levels of screen time were associated with greater hyperactivity/inattention and internalizing problems. Greater amounts of time on screen-based sedentary behavior were also linked to lower scores on self-esteem. In another systematic review, moderate evidence supported the relationship between screen use and low self-esteem [34].

adolescents who were on screen time and sedentary for more than 2 to 3 hours per day.The poor mental health status included psychological distress, loneliness, depression, anxiety and suicide ideation.

Depression, anxiety, loneliness and low self-esteem have been noted in several studies on excessive gaming. In a latent class analysis on a sample of 9733 adolescents, those who were heavy game players had more depressive symptoms [35]. Friendship quality was noted to attenuate depression in some male gamers. Those who were very socially active online reported fewer symptoms of game addiction and depression. In another study on a sample from Sweden ( $\mathrm{N}=1868$ adolescents), problematic gaming was associated with psychiatric symptoms including depression, anxiety and ADHD [36]. In a study on a Finnish sample, problematic gaming as measured by the game addiction scale was associated with psychological symptoms and physical health [37]. A multiple linear regression indicated not only a relationship between the amount of weekly gaming and depression but also associations between gaming and anxiety symptoms, fatigue and sleep problems. These were also related to a preference for online social interaction, a variable that is rarely measured but is likely related to the loneliness that has been reported for adolescents who are gaming addicted.

Cyberbullying perpetration/victimization has also resulted from online gaming just as it has from Internet addiction [13]. In a study on 2315 high school students from Taiwan, online game use and internet use in $10^{\text {th }}$ grade was a significant predictor of gaming one year later, and gaming also contributed to the emergence of cyberbullying perpetration/victimization in $11^{\text {th }}$ grade [38].

Substance use is another addictive behavior that has been noted in teenagers engaging in excessive video games (at least 30 hours per week versus onefive hours per week) [39]. In this study on two large samples of eighth and $10^{\text {th }}$ graders in the US $(\mathrm{N}=7313$ and 8079$)$, those who played online games at least 30 hours per week reported significantly more instances of substance use than those who played one-five hours per week.

It is not surprising given all the effects of Internet gaming disorder that those adolescents would have more family conflict and a poor family relationship [40]. In this study, rules about gaming use were important for males but gaming was banned for females. Parental monitoring was, surprisingly, associated with Internet gaming disorder in this study, but possibly because the monitoring was excessively restrictive, as is suggested by the parents banning Internet gaming for females.

Although parental attitudes have been assessed in a number of studies including the research just described [40], attitudes of the adolescents themselves have rarely been tapped. An exception is a small interview study conducted with Hong Kong adolescents [41]. As already noted, approximately $94 \%$ of Hong Kong adolescents have engaged in Internet gaming [7]. In the Hong Kong adolescents' attitudes study, 13 male high school students were interviewed at two Internet cafés [41]. Of the 13 adolescents, five were categorized as pathological gamers and 8 were problem gamers. The students described the benefits of gaming as including improving their responsiveness and quick thinking, their intellectual agility, their cognitive techniques, meeting new friends and becoming sociable, fostering social support and teamwork and having fun and satisfaction. They suggested that the harms of gaming addiction were poor academic performance, the loss of interest in other activities, emotional distress, disrupted friendship with non-gaming peers, difficult family relationships and financial problems and physical harms. They further suggested that the psychological factors of gaming addiction included low self-esteem, gaming for killing time and to achieve satisfaction, coping with problems and negative emotions, a desire for aggressive exciting experiences, and being obsessed with achieving higher rankings in their games. Interestingly, their list of harms was at odds with their list of benefits. For example, boosting cognitive techniques and intellectual ability were mentioned as benefits but at the same time poor academic performance was listed as a harm. Another example was their suggesting that meeting new friends and becoming sociable were benefits, but then they spoke of disrupted friendships with non-gaming peers as being a harm. 
Nonetheless, this list about positive and negative effects should be useful in informing prevention/intervention research (Table 2).

\section{Risk Factors for Internet Gaming Addiction}

Risk factors have been studied as frequently as effects of Internet gaming addiction in adolescents. The risk factors in the recent literature have included invitation by peers, hours of gaming, impulsivity, sensation-seeking, externalizing behaviors and aggressivity. Although these are typically researched as single factor studies, the Hong Kong adolescents in the study just described listed several risk factors, most of which are not featured in the recent literature on Internet gaming addiction in adolescents [41]. In this study, the risk factors listed by the Hong Kong adolescents included several social and environmental risk factors that have also been studied as effects of Internet gaming addiction. These include poor family relationships, lack of parental supervision, perceived parental approval of their gaming, early gaming experiences, peer pressure, accessibility to Internet cafés and aggressive activities at Internet cafés,

In a study on peer influences among adolescents in Taiwan, 104 Junior high school students completed scales on Internet addiction, parental influence, peer influence and positive outcome expectancy for Internet gaming [42]. The results suggested that three types of peer influence included peers' positive attitudes toward Internet gaming, the frequency of Internet game use by their peers, an invitation to play by their peers and positive outcome expectations. These were all significantly positively correlated with Internet gaming addiction. In contrast, parental influences had very minimal effect on positive outcome expectancy. In a structural equations modeling analysis, however, only the parents' invitation to play Internet games predicted addiction severity. In contrast, in a mediation analysis, peers' positive attitudes toward game use and the frequency of peers' Internet game use positively predicted gaming addiction and positive outcome expectancy was a significant mediator. These findings illustrate the contradictory findings revealed by different types of data analyses. And, the structural equations model only explained $25 \%$ of the variance on internet gaming addiction, which suggests that many other factors are involved in addition to parent and peer influences.

Typically, the amount of time spent gaming has been considered a risk factor for gaming addiction. Surprisingly, though, the number of different games has not been explored in the recent literature except in one study. In that study, both the amount of time spent on gaming and the versatility or the number of different videogame genres engaged in by male high school students were assessed, and both the hours of gaming and the versatility of gaming were risk factors for gaming addiction [43].

Other risk factors for Internet gaming addiction have been explored including personality traits and problematic behaviors. These have included impulsivity, sensation-seeking, externalizing and internalizing behaviors. In a study on 920 secondary school Chinese students, the Game Addiction Scale and the Big Five Inventory were given to the students [44]. Less conscientiousness and low openness were significantly associated with gaming addiction. In another study from China, 375 male adolescents completed anonymous questionnaires regarding sensation seeking, affective associations with online games, impulsivity and online gaming addiction [45]. Each of these variables was positively associated with online gaming addiction. Positive affective associations mediated the relationship between sensationseeking and online gaming addiction. And, impulsivity moderated the relationship between positive affective associations and online gaming addiction. These associations were stronger for high versus low impulsivity adolescents. In a similar study on 1293 Chinese adolescents, another mediation model was explored assessing whether deviant peer affiliation mediated the relationship between sensation-seeking and adolescent Internet gaming addiction [46]. Structural equations models revealed a positive association between sensation-seeking and adolescent Internet gaming addiction. That relationship was partially mediated by deviant peer affiliation and indirectly moderated by parental knowledge.
The indirect path from sensation-seeking to gaming addiction was stronger for adolescents who had parents with low knowledge about their gaming. The focus on sensation-seeking in the behavioral literature is interesting in light of the focus on reward-seeking in the fMRI literature inasmuch as sensation-seeking may be closely related to reward-seeking for adolescents. Externalizing and internalizing behaviors have been considered risk factors for Internet gaming addiction. In a study on externalizing/internalizing, a sample of 86 adolescents who were residing on an addictive behavior unit were assessed for comorbid disorders [47]. Sixty-nine percent met diagnostic criteria for Internet gaming disorder. Of these, 53\% of the sample presented with an externalizing profile while $46 \%$ presented with an internalizing profile. The internalizing adolescents had a family history of psychiatric disorders, difficult social relationships and using gaming as an escape from discomfort, and they also had comorbid mood, anxiety and personality disorders. The externalizing adolescents showed improvement after 3 months of treatment, unlike the internalizing adolescents, possibly because the internalizers had family history problems and comorbid disorders that complicated their improvement (Table 3).

Altered Autonomic and Central Nervous System Function Several autonomic nervous system functions have been notably altered by Internet gaming disorder including heart rate variability, eye blinking, and saccadic eye movements as well as respiratory rate. In addition, several central nervous system functions have been affected. Data from both resting activity and stressful task and negative stimuli-related fMRI scans have also revealed modifications in connectivity and gray and white matter in brain centers that modulate impulsivity and reward-seeking. Although many of these results are correlated with the behavioral effects already noted, once again causality or direction of effects cannot be determined. These could be effects/comorbidities deriving from Internet gaming addiction or risk factors contributing to Internet gaming addiction (Table 4).

\section{Altered Autonomic Nervous System Function}

Heart rate variability has been sampled in at least two studies. In a study on 68 Korean adolescent males, most heart rate variability parameters differed between Internet gaming addiction (IGA) adolescents and non- IGA groups [48]. Heart rate variability was inversely associated with type D personality (distressed personality) scores. In a study by a different research group, gaming craving was aroused by a short video clip showing gameplay videos of three addictive games with 27 adolescents who had mild to severe Internet gaming disorder [49]. Once again, heart rate variability was decreased as well as the number of eye blinks and saccadic eye movements, and mean respiratory rate also increased.

\section{Altered Central Nervous System Function}

Due to the increased reporting of impulsivity, aggression and dysfunction in emotion regulation in adolescents with Internet gaming addiction, several imaging studies have been conducted. Altered central nervous system function in adolescents with internet gaming disorder has been demonstrated by a number of fMRI studies. These have included resting state fMRI scans as well as scans during and following different stressful tasks and negative stimuli including swearwords and angry facial stimuli. The studies have basically shown altered activation/connectivity in the prefrontal cortex (known to modulate impulsivity), the ventral striatum (associated with reward-seeking) and the amygdala (associated with aggression). In addition, gray matter volume and white matter volume have been reduced in adolescents with gaming addiction

\section{Resting state/ brain image studies}

A systematic review of studies conducted since the 2003 DSM V classification of Internet Gaming Disorder yielded several brain imaging studies [50]. Most of these indicated impaired cognitive control associated with abnormal function in the prefrontal cortex and ventral striatum. Behavioral problems that were related included sleep disturbance, inferior school work, and low-quality parent-adolescent relationships. Most of the fMRI studies have yielded alterations in the interhemispheric resting-state functional connectivity. 
In a morphometric analysis by another research group, those with Internet In one study, 17 adolescents with internet gaming addiction versus 24 healthy controls were shown to have altered interhemispheric resting state functional connectivity in the bilateral prefrontal lobe [51]. In a similar study on spontaneous brain activity in adolescents with online gaming addiction, those with addiction versus those without addiction showed a significant increase in the amplitude of low frequency fluctuation values in the orbital frontal cortex as well as other areas that have been detected in previous addiction studies [52]. These values were correlated with the duration of online gaming addiction. In another resting-state fMRI scan study, adolescents with Internet gaming addiction who had longer Internet use per week exhibited increased functional connectivity in some areas of the brain and decreased functional connectivity in others, suggesting a pattern that was consistent with those in patients with substance addiction [53]. In still another resting state functional connectivity study, increased disturbance was shown in regions involved in working memory and attention processing [54]. Inasmuch as the adolescents with Internet gaming disorder did not differ from normal controls in their behavioral performance on working memory and attention, the authors interpreted their increased connectivity findings as a compensatory mechanism for maintaining normal performance

\section{Stressful task/brain imaging studies}

Other studies have used stressful tasks during functional magnetic resonance imaging experiments to assess modulation of impulsivity. For example, in a balloon analogue risk task to assess the modulation of risk level (the probability of balloon explosions), there was a reduced modulation of risk-taking which was significantly related to a decrease in sensitivity to that risk in the right dorsal lateral prefrontal cortex of adolescents with internet gaming disorder [55]. That the right dorsal lateral prefrontal cortex was less sensitive to risk in these adolescents was interpreted as contributing to their greater impulsivity. In a similar study by the same research group, apparently on the same database, additional areas of the brain were implicated following the same balloon analogue risk tasks including the ventral striatum that involves rewardseeking and the hippocampus/para-hippocampus involved in emotionrelated learning [56]. In a response-inhibition go/no go study also designed to assess areas involved in impulsivity, the addicted and nonaddicted adolescents' performance on the task did not differ, but the addicted group showed impaired activity in the prefrontal cortex that was associated with impulsivity [53]. The authors suggested that the impaired function of the prefrontal cortex normally involved in modulating impulsivity may relate to the high impulsivity and the internet gaming addiction in adolescents.

\section{Negative stimuli/brain imaging studies}

Negative stimuli have also been used in fMRI studies including swearwords and angry facial stimuli. In the swearword versus negative word condition, adolescents with IGD showed reduced activation in the orbital frontal cortex related to cognitive control, in the dorsal anterior cingulate cortex related to social rejection, and in the amygdala involving control of aggression [57]. In a study presenting angry facial stimuli to interfere with performance on a match to sample task, the Internet gaming disorder group showed weaker dorsal anterior cingulate cortex activation which was correlated with higher cognitive impulsivity [58]. These data are similar to those noted for the right dorsal lateral prefrontal cortex being less sensitive to risk during the balloon analogue risk task, suggesting again greater impulsivity in adolescents with internet gaming addiction [55].

Structural abnormalities in brain gray matter and white matter volume have also been associated with impulsivity and Internet gaming disorder. In a morphometric study, negative correlations were noted between impulsivity scores and gray matter volume of the right dorsomedial prefrontal cortex as well as the orbital frontal cortex and the right amygdala [59]. These data like those from the fMRI connectivity studies suggest that dysfunction of these areas that are involved in behavior inhibition, attention and emotion regulation may be contributing to the impulsivity noted in adolescents with Internet gaming addiction [59]. cingulate cortex involved in executive control [60]. The gray matter volume in the left ventral lateral prefrontal cortex was negatively correlated with lifetime usage of internet gaming, again attributed to excessive Internet gaming during adolescence. Still another group has reported less gray matter volume in adolescents with Internet gaming addiction versus healthy controls in the anterior cingulate cortex and the dorsolateral prefrontal cortex during a go-no go task, suggesting reduced cognitive control [61]. In a study by the same group that reported reduced gray matter on a sample of Internet gaming disorder adolescents versus healthy controls [59], white matter changes were also correlated with greater impulsivity [54].

\section{Genetic Factors}

In a cross-sectional study on 230 male high school students in South Korea, several stress- related candidate genes were genotyped to examine the relationship of these stress-related genes to Internet gaming addiction [62]. The AA genotype and the A allele of the CRHR1 gene were associated with greater odds of belonging to the Internet gaming addiction group indicating that the polymorphism of that gene may plan an important role in the susceptibility to IGD in Korean adolescent males. In a later gene study by the same research group, leukocyte telomere length (LTL) was examined in the same sample as previously reported [62]. In this paper, leukocyte telomere length was calculated as the telomere/single copy ratio (T/S ratio) [63]. In a multiple linear regression model, age, daily Internet gaming time and epinephrine levels were statistically predictive of the $\mathrm{T} / \mathrm{S}$ ratio, suggesting that Internet gaming may induce LTL shortening in male adolescents which may be attributable to the higher epinephrine levels noted in those adolescents.

\section{Prevention/Intervention for Internet Gaming Disorder}

Given the significant prevalence, severity and comorbid conditions associated with Internet gaming addiction, it is surprising that relatively few intervention studies appeared in the recent literature. Those have included parental monitoring, cognitive behavior therapy plus parent education, cue exposure therapy, and exercise.

In a study on parental monitoring, a three-way cross-lagged panel model was used to explore the relationship between parental monitoring and Internet gaming disorder [64]. In this sample of 1490 adolescents, parental monitoring at time 1 predicted lower Internet gaming disorder at time 2 and greater Internet gaming disorder at time 2 predicted less parental monitoring at time 3 . The father-adolescent relationship patterns had a reciprocal indirect effect on the correlation between parental monitoring and Internet gaming disorder but the mother-adolescent relationship did not.

In a study that combined cognitive behavior therapy with parental education, that intervention versus cognitive behavior therapy alone did not yield differences on the Million Adolescent Personality Inventory scores as well as the diagnostic criteria for Internet gaming disorder [65]. However, the group who only received cognitive behavior therapy showed higher dropout rates during the treatment period. In a study that created a virtual Internet café, the adolescents were exposed to different tasks while cravings were measured for the urge to play a game after exposure to each task [66]. The virtual Internet café therapy might be a useful treatment for gaming cravings.

Active video gaming, as already discussed, and exercise might impact the energy and food intake level of adolescents with Internet gaming addiction. In a study that compared exercise (cycling) and an active videogame (boxing), the games were designed to generate the same energy expenditure [67]. The moderate-intensity exercise provided better energy balance than the active video gaming by affecting both energy expenditure and energy intake (Table 5).

\section{Limitations of the Literature and Future Directions}

Research on prevalence, risk factors and effects data comprise most of the recent literature on gaming addiction in adolescents. Only a few interventions were noted in this recent literature including monitoring by parents as well as cognitive behavior therapy. 
Methodological limitations of this research include reliance on selfreport questionnaires that often do not include time spent online gaming and online gaming behaviors. And, the self-report data are discordant with clinical interview data, as was noted in at least one recent study [68]. Smaller sample interview, observational and laboratory studies are needed to understand specific gaming behaviors and the risk factors associated with gaming addiction in adolescents. For example, social anxiety would seem to be associated with gaming which, in turn, may be a safer way of interacting with peers.

Different measures have been used in different studies making it problematic to compare prevalence, effects and risk factors across studies. Cultural differences exist, as noted, but different measures have been used in different cultures. And the scales are typically long and based on pathological conditions. Some have criticized the developers of the scales for borrowing criteria from other addiction research like that of substance abuse. And, using the DSM-V criteria for internet gaming disorder has yielded false positives as well as false negatives. Gaming addiction is associated with so many other demographic, psychological and behavioral problems as well as comorbid conditions like cyberbullying and depression and addictions like substance abuse. Determining the degree to which each of these contributes to the variance on gaming addiction is important. Research is also missing on important variables like peer relationships/rejection as potential risk factors. Like other literature on adolescent problems, this research is limited by primarily deriving from self-report and parent report and by the absence of longitudinal data that might inform whether the behavioral and brain data being reported are effects of or risk factors for internet gaming addiction. More multivariate research is needed as well as profile/regression/structural equation modeling that can identify the relative variance explained by these variables. Identifying high risk profiles could then be translated into clinical interventions.

Most of the recent studies are correlational so that the direction of effects cannot be determined. The usual problems of correlation analyses apply to these studies including the lack of control over confounding variables. Regression, mediation/moderation and structural equations analysis models could have been used in these large sample studies to control for potentially confounding variables and to determine the relative contribution of these variables to the outcome variance on gaming addiction in adolescents .

Interventions that have been effectively used with other addictions could be explored with adolescents who are experiencing gaming addiction including, for example, the parent monitoring protocols, exercise programs, massage therapy, yoga, meditation and cognitive behavior therapy. Further, the occurrence of gaming addiction and other addictions like internet addiction as early as pre-adolescence highlights the need for school-based education programs for both parents and students along with teacher and peer monitoring of these addictive behaviors.

Unfortunately, the internet and cell-phone technology that was intended for communication and educational purposes has become addictive and problematic for many aspects of the health and wellbeing of younger and younger adolescents. The survey studies reviewed here have highlighted the prevalence, risks and effects of gaming addiction. However, more small-scale empirical studies are needed to explore the specific gaming addiction behaviors Research is also missing on peer relationships/rejection as potential risk factors. Like other literature on adolescent problems, this research is limited by primarily deriving from self-report and parent report and by the absence of longitudinal data that might inform whether the behavioral and brain data being reported are effects of or risk factors for internet gaming addiction. And, research is needed on related addiction behaviors, the personality and non-gaming activity profiles of the adolescents and the underlying mechanisms to inform the even more needed early intervention/prevention studies.
Table 1: Prevalence of internet gaming and internet gaming disorder.

\begin{tabular}{|l|l|l|}
\hline Prevalence & Location & First Author \\
\hline $19 \%$ & U.S. & Lee (2017) [3] \\
\hline $56 \%$ & U.S. & Papay (2013) [4] \\
\hline $80 \%$ & Saudi Arabia & Awadalla [5] \\
\hline $85 \%$ & Australia & Rikkers [6] \\
\hline $94 \%$ & Hong Kong & Wang (2014) [7] \\
\hline $2-6 \%$ & systematic review & Paulus [11] \\
\hline $5 \%$ & meta-analysis & Fam [12] \\
\hline $1.6 \%$ & European countries & Muller [18] \\
\hline $1.2 \%$ & Germany & Rehbein [19] \\
\hline $9 \%$ & Paris & Bonnaire [20] \\
\hline $2.5 \%$ & Slovenia & Pontes [21] \\
\hline $6 \%$ & S. Korea & Yu [22] \\
\hline $3 \%$ & Taiwan & Chiu [23] \\
\hline $12 \%$ & Canada & Veselka [24] \\
\hline
\end{tabular}

Table 2: Effects of internet gaming addiction in adolescents.

\begin{tabular}{|l|l|}
\hline Effects & First Author \\
\hline$<$ school performance & van Roorj [32] \\
\hline Neg. self-esteem & van Roorj, Suchert, Hoare [32-34] \\
\hline Loneliness & van Roorj, Hoare [32,34] \\
\hline Anxiety & $\begin{array}{l}\text { van Roorj, Hoare, Vadlin, Mannikko } \\
\text { [32,34,36,37] }\end{array}$ \\
\hline Depressed mood & $\begin{array}{l}\text { van Roorj, Hoare, Colder-Carras, Vadlin, } \\
\text { Mannikko [32,34-37] }\end{array}$ \\
\hline$>$ nicotine & $\begin{array}{l}\text { van Roorj, Hoare, Colder-Carras, Vadlin, } \\
\text { Mannikko [32,34-37] }\end{array}$ \\
\hline$>$ alcohol & $\begin{array}{l}\text { van Roorj, Hoare, Colder-Carras, Vadlin, } \\
\text { Mannikko [32,34-37] }\end{array}$ \\
\hline$>$ cannabis & $\begin{array}{l}\text { van Roorj, Hoare, Colder-Carras, Vadlin, } \\
\text { Mannikko [32,34-37] }\end{array}$ \\
\hline ADHD & Vadlin [36] \\
\hline Hyperactivity & Suchert [33] \\
\hline Internalizing & Suchert [33] \\
\hline Suicide ideation & Hoare [34] \\
\hline Sleep problems & Mannikko [37] \\
\hline Cyberbullying & Chang [38] \\
\hline Substance use & Turel [39] \\
\hline Family conflict & Bonnaire [40] \\
\hline
\end{tabular}

Table 3: Risk factors for internet gaming disorder.

\begin{tabular}{|l|l|}
\hline Risk factors & First Author \\
\hline Poor family relationships & Wong [41] \\
\hline <parental supervision & Wong [41] \\
\hline Perceived parental approval & Wong [41] \\
\hline Early gaming experiences & Wong [41] \\
\hline Peer pressure internet & Wong [41] \\
\hline $\begin{array}{l}\text { Accessibility to } \\
\text { cafes }\end{array}$ & Wong [41] \\
\hline Aggressive activities & Wong [41] \\
\hline Frequency of use by peers & Wu [42] \\
\hline Invitation to play by peers & Wu [42] \\
\hline Parents' invitation to play & Wu [42] \\
\hline Amount of time playing & Donati [43] \\
\hline Versatility of gaming & Donati [43] \\
\hline <conscientiousness & Wang [44] \\
\hline$<$ openness & Wang [44] \\
\hline Sensation seeking & Wang, Hu [44,45] \\
\hline Impulsivity & Wang, Hu, Tian [44-46] \\
\hline Deviant peer affiliation & Tian [46] \\
\hline Externalizing & Martin-Fernandez [47] \\
\hline Internalizing & Martin-Fernandez [47] \\
\hline & \\
\hline
\end{tabular}


Table 4: Altered autonomic and central nervous system function in internet gaming addiction in adolescents.

\begin{tabular}{|c|c|}
\hline Autonomic dysfunction & First Author \\
\hline$<$ heart rate variability & $\operatorname{Kim}(2016), \operatorname{Kim}(2018)[48,69]$ \\
\hline >eye blinking & Kim (2018) [69] \\
\hline >saccadic eye movements & $\operatorname{Kim}(2018)$ [69] \\
\hline$>$ respiratory rate & Kim (2018) [69] \\
\hline $\begin{array}{l}\text { Central nervous system } \\
\text { dysfunction }\end{array}$ & First Author \\
\hline $\begin{array}{l}\text { Abnormal function in } \\
\text { prefrontal cortex }\end{array}$ & $\begin{array}{l}\text { Sugaya, Wang (2015), Yuan, } \\
\text { Ding [50-53] }\end{array}$ \\
\hline $\begin{array}{l}\text { Abnormal function in ventral } \\
\text { striatum }\end{array}$ & $\begin{array}{l}\text { Sugaya, Wang (2015), Yuan, } \\
\text { Ding, Qi (2016) }[50-53,56]\end{array}$ \\
\hline $\begin{array}{l}\text { Abnormal function in dorsal } \\
\text { lateral prefrontal cortex }\end{array}$ & $\begin{array}{l}\text { Qi, (2015), Lee (2015), Wang } \\
(2015)[56,58,61]\end{array}$ \\
\hline $\begin{array}{l}\text { Abnormal function in orbital } \\
\text { frontal cortex }\end{array}$ & Chun [57] \\
\hline $\begin{array}{l}\text { Abnormal function in the } \\
\text { amygdala }\end{array}$ & Chun [57] \\
\hline $\begin{array}{l}\text { Structural abnormalities in } \\
\text { gray matter volume }\end{array}$ & Du (2016), Lee $(2018)[59,60]$ \\
\hline $\begin{array}{l}\text { Structural abnormalities in } \\
\text { white matter volume }\end{array}$ & Du (2017) [70] \\
\hline
\end{tabular}

Table 5: Prevention/intervention for internet gaming addiction in adolescents.

\begin{tabular}{|l|l|}
\hline Intervention & First Author \\
\hline Parental monitoring & Su [64] \\
\hline $\begin{array}{l}\text { Cognitive behavior therapy plus } \\
\text { parental education }\end{array}$ & Gonzalez-Bueso [65] \\
\hline Cue exposure therapy & Shin [66] \\
\hline Exercise & Chaput [67] \\
\hline
\end{tabular}

\section{References}

1. Irby G (2019) The Struggle Itself. Spiral 1: 30-31.

2. Yang L, Cao C, Kantor ED, Nguyen LH, Zheng X, et al. (2019) Trends in Sedentary Behavior Among the U.S. Population, 20012016. JAMA 321(16): 1587-1597.

3. Lee HH, Sung JH, Lee JY, Lee JE (2017) Differences by Sex in Association of Mental Health with Video Gaming or Other NonAcademic Computer Use Among US Adolescents. Prev Chronic Dis 14: E117.

4. Pápay O, Urbán R, Griffiths MD, Nagygyörgy K, Farkas J, et al. (2013) Psychometric Properties of the Problematic Online Gaming Questionnaire Short-Form and Pprevalence of Problematic Online Gaming in a National Sample of Adolescents. Cyberpsychol Behav soc Netw 16(5): 340-348.

5. Awadalla N, Hadram M, Alshahrani A, Hadram Y (2017) Association of Video Gaming With Some Risky Behaviors of Secondary School Adolescents in Abha, Southwestern Saudi Arabia. J Egypt Public Health Assoc 92(1): 18-28.

6. Rikkers W, Lawrence D, Hafekost J, Zubrick SR (2016) Internet Use and Electronic Gaming by Children and Adolescents With Emotional and Behavioral Problems in Australia- Results From the Second Child and Adolescent Survey of Mental Health and Wellbeing. BMC Public Health 16: 399.

7. Wang CW, Chan CL, Mak KK, Ho SY, Wong PW, et al. (2014) Prevalence and Correlates of Video and Internet Gaming Addiction Among Hong Kong Adolescents: A Pilot Study. ScientificWorldJournal 2014: 874648.

8. Gentile DA, Bailey K, Bavelier D, Brockmyer JF, Cash H, et al. (2017) Internet Gaming Disorder in Children and Adolescents. Pediatrics 140: S81-S85.

9. Fam JY (2018) Prevalence of Internet Gaming Disorder in Adolescents: A Meta-Analysis Across Three Decades. Scand J Psychol 59(5): 524-531.
10. Koo HJ, Han DH, Park SY, Kwon JH (2017) The Structured Clinical Interview for DSM-5 Internet Gaming Disorder: Development and Validation for Diagnosing IGD in Adolescents. Psychiatry Investig 14(1): 21-29.

11. Vadlin S, Aslund C, Nilsson KW (2015) Development and Content Validity of a Screening Instrument for Gaming Addiction in Adolescents: The Gaming Addiction Identification Test (GAIT). Scand J Psychol 56(4): 458-466.

12. Paulus FW, Ohmann S, von Gontard A, Popow C (2018) Internet Gaming Disorder in Children and Adolescents: A Systematic Review. Dev Med Child Neurol 60(7): 645-659.

13. Field T (2018a) Internet Addiction in Adolescents: A Review. J Addict Ther 1: 1-11.

14. Field T (2018b) Cyberbullying: A Narrative Review. J Addict Ther Res 2: 10-27.

15. Field T (2019a) Adolescent Depression: A Narrative Review. (In Review).

16. Field T (2019b) Suicide Ideation and Attempts in Adolescents: A Narrative Review. (In Review).

17. Field T (2019c) Violence in Adolescents; A Narrative Review (In Review).

18. Muller KW, Janikian M, Dreier M, Wolfing K, Beutel ME, et al. (2015) Regular Gaming Behavior and Internet Gaming Disorder in European Adolescents: Results from a Cross-National Representative Survey of Prevalence, Predictors, and Psychopathological Correlates. Eur Child Adol Psychiatry 24(5): 565-574.

19. Rehbein F, Kliem S, Baier D, Moble T, Petry NM (2015) Prevalence of Internet Gaming Disorder in German Adolescents: Diagnostic Contribution of the Nine DSM-5 Criteria in a State-Wide Representative Sample. Addict 110(5): 842-851.

20. Bonnaire C, Phan O (2017) [Negative Perceptions of the Risks Associated With Gaming in Young Adolescents: An Exploratory Study to Help Thinking About a Prevention Program]. Arch Pediatrics 24(7): 607-617.

21. Pontes HM, Macur M, Griffiths MD (2016) Internet Gaming Disorder Among Slovenian Primary School Children: Findings From a Nationally Representative Sample of Adolescents. J Behav Addict 5(2): 304-310.

22. Yu H, Cho J (2016) Prevalence of Internet Gaming Disorder among Korean Adolescents and Associations with Non-Psychotic Psychological Symptoms, and Physical Aggression. Am J Health Behav 40(6): 705-716.

23. Chiu YC, Pan YC, Lin YH (2018) Chinese Adaptation of the Ten- Item Internet Gaming Disorder Test and Prevalence Estimate of Internet Gaming Disorder among Adolescents in Taiwan. J Behav Addict 7(3): 719-726.

24. Veselka L, Wijesingha R, Leatherdale ST, Turner NE, Elton- Marshall T (2018) Factors Associated With Social Casino Gaming Among Adolescents Across Game Types. BMC Public Health 18(1): 1167.

25. Simons M, de Vet E, Brug J, Seidell J, Chinapaw MJ (2014) Active Gaming and Non-Active Video Gaming Among Dutch Adolescents: Who Plays and How Much? J Sci Med Sport 17(6): 597-601.

26. Simons M, Brug J, Chinapaw MJ, de Boer M, Seidell J, et al. (2015a) Replacing Non-Active Video Gaming by Active Video Gaming to Prevent Excessive Weight Gain in Adolescents. PLoS One 10(7): e0126023.

27. Simons M, Chinapaw MJ, Brug J, Seidell J, de Vet E (2015) Associations between Active Video Gaming and Other EnergyBalance Related Behaviors in Adolescents: A 24-Hour Recall Diary Study. Int J Behav Nutr Phys Act Mar 12: 32.

28. Simons M, Bernaards C, Slinger J (2012) Active Gaming in Dutch Adolescents: A Descriptive Study. Int J Behav Nutr Phys Act Mar 9: 118.

29. Simons M, de Vet E, Chinapaw MJ, de Boer M, Seidell JC, et al. (2014) Personal, Social, and Game-Related Correlates of Active and Non-Active Gaming among Dutch Gaming Adolescents: SurveyBased Multivariable, multilevel Logistic Regression Analyses. JMIR Serious Games 2(1): e4. 
30. Trisolini DC, Petilli MA, Daini R (2018) Is Action Video Gaming Related to Sustained Attention of Adolescents? Q J Exp Psychol (Hove) 71(5): 1033-1039.

31. Vadlin S, Aslund C, Nilsson KW (2018) A Longitudinal Study of the Individual- and Group-Level Problematic Gambling Among Swedish Adolescents. Brain Behav 8(4): e00949.

32. VAN Rooij AJ, Kuss DJ, Griffiths MD, Shorter GW, Schoenmakers MT, et al. (2014) The Co-Occurrence of Problematic Video Gaming, Substance Use, and Psychosocial Problems in Adolescents. J Behav Addict 3(3): 157-165.

33. Suchert V, Hanewinkel R, Isensee B (2015) Sedentary Behavior and Indicators of Mental Health in School-Aged Children and Adolescents: A systematic review. Prev Med 76: 48-57.

34. Hoare E, Milton K, Foster C, Allender S (2016) The Associations Between Sedentary Behavior and Mental Health Among Adolescents: A Systematic Review. Int J Behav Nutr Phys Act 13(1): 108 .

35. Colder Carras M, Van Rooij AJ, Van de Mheen D, Musci R, Xue QL, et al. (2017) Video gaming in a hyperconnected world: A Cross-Sectional Study of Heavy Gaming, Problematic Gaming Symptoms, and Online Socializing in Adolescents. Comput Human Behav 68: 472-479.

36. Vadlin S, Åslund C, Hellström C, Nilsson KW (2016) Associations Between Problematic Gaming and Psychiatric Symptoms Among Adolescents in Two Samples. Addict Behav 61: 8-15.

37. Mannikko N, Billieux J, Kaariainen M (2015) Problematic Digital Gaming Behavior and its Relation to the Psychological, Social and Physical Health of Finnish Adolescents and Young Adults. J Addict 4(4): 281-288.

38. Chang FC, Chiu CH, Miao NF, Chen PH, Lee CM, et al. (2015) Online Gaming and Risks Predict Cyberbullying Perpetration and Victimization in Adolescents. Int J Pub Health 60(2): 257-266.

39. Turel O, Bechara A (2019) Little Video-Gaming in Adolescents Can be Protective, but Too Much is Associated With Increased Substance Use. Subst Use Misuse: 54(3): 384-395.

40. Bonnaire C, Phan O (2017) Relationships Between Parental Attitudes, Family Functioning and Internet Gaming Disorder in Adolescents Attending School. Psychiatry Res 255: 104-110.

41. Wong IL, Lam MP (2016) Gaming Behavior and Addiction Among Hong Kong Adolescents. Asian J Gambl Issues Public Health 6(1): 6.

42. Wu JY, Ko HC, Wong TY, Wu LA, Oei TP (2016) Positive Outcome Expectancy Mediates the Relationship Between Peer Influence and Internet Gaming Addiction Among Adolescents in Taiwan. Cyberpsychol Behav Soc Netw 19(1): 49-55.

43. Donati MA, Chiesi F, Ammannato G, Primi C (2015) Versatility and Addiction in Gaming: The Number of Video-Game Genres Played in Associated With Pathological Gaming in Male Adolescents. Cyberpsychol Behav Soc Netw 18(2): 129-132.

44. Wang CW, Ho RT, Chan CL, Tse S (2015) Exploring Personality Characteristics of Chinese Adolescents With Internet-Related Addictive Behaviors: Trait Differences for Gaming Addiction and Social Networking Addiction. Addict Behav 42: 32-35.

45. Hu J, Zhen S, Yu C, Zhang Q, Zhang W (2017) Sensation Seeking and Online Gaming Addiction in Adolescents: A Moderated Mediation Model of Positive Affective Association and Impulsivity. Front Psychol 8: 699.

46. Tian Y, Yu C, Lin S, Lu J, Liu Y, et al. (2019) Sensation Seeking, Deviant Peer Affiliation, and Internet Gaming Addiction Among Chinese Adolescents: The Moderating Effect of Parental Knowledge. Front Psychol 9: 2727.

47. Martín-Fernández M, Matalí JL, García-Sánchez S, Pardo M, Lleras M, et al. (2016) Adolescents With Internet Gaming Disorder (IGD): Profiles and Treatment Response. Adicciones, 29(2): 125133.

48. Du X, Yang Y, Gao P, Qi X1, Du G, et al. (2017) Compensatory Increase of Functional Connectivity Density in Adolescents With Gaming Disorder. Brain Imaging Behav 11: 1901-1909. 
Kim N, Hughes TL, Park CG, Quinn L, Kong ID (2016) Altered Autonomic Functions and Distressed Personality Traits in Male Adolescents With Internet Gaming Addiction. Cyberpsychol Behav Soc Netw 19(11): 667-673.

50. Kim H, Ha J, Chang WD, Park W, Kim L, et al. (2018) Detection of Craving for Gaming in Adolescents With Internet Gaming Disorder Using Multimodal Biosignals. Sensors (Basel) 18(1); Pii: E102.

51. Sugaya N, Shirasaka T, Takahashi K, Kanda H (2019) BioPsychosocial Factors of Children and Adolescents With Internet Gaming Disorder: A Systematic Review. Biopsychosoc Med 13: 3.

52. Wang Y, Yin Y, Sun YW, Zhou Y, Chen X, et al. (2015) Decreased Prefrontal Lobe Interhemispheric Functional Connectivity in Adolescents With Internet Gaming Disorder: A Primary Study Using Resting-State FMRI. PLoS One 10(3): e0118733.

53. Yuan K, Yin C, Cheng P, Yang X, Dong T, et al. (2013) Amplitude of Low Frequency Fluctuation Abnormalities in Adolescents With Online Gaming Addiction. PLoS One 8(11): e78708.

54. Ding WN, Sun JH, Sun YW, Chen X, Zhou Y, et al. (2014) Trait Impulsivity and Impaired Prefrontal Impulse Inhibition Function in Adolescents With Internet Gaming Addiction Revealed by a Go/No- Go FMRI Study. Behav Brian Funct 10: 20.

55. Qi X, Du X, Yang Y, Du G, Gao P, et al. (2015) Decreased Modulation by the Risk Level on the Brain Activation During Decision Making in Adolescents With Internet Gaming Disorder. Front Behav Neurosci 9: 296.

56. Qi X, Yang Y, Dai S, Gao P, Du X, et al. (2016) Effects of Outcome on the Covariance Between Risk Level and Brain Activity in Adolescents With Internet Gaming Disorder. Neuroimage Clin 12: 845-851.

57. Chun JW, Choi J, Cho H, Lee SK, Kim DJ (2015) Dysfunction of the Frontolimbic Region During Swear Word Processing in Young Adolescents With Internet Gaming Disorder. Transl Psychiatry 5:e624.

58. Lee J, Lee S, Chun JW, Cho H, Kim DJ, et al. (2015) Compromised Prefrontal Cognitive Control Over Emotional Internet Gaming Disorder. Cyberpsychol Behav Soc Netw 18(11): 661-668.

59. Du X, Qi X, Yang Y, Du G, Gao P, et al. (2016) Altered Structural Correlates of Impulsivity in Adolescents With Internet Gaming Disorder. Front Hum Neurosci 10: 4.

60. Lee D, Namkoong K, Lee J, Jung YC (2018) Abnormal Gray Matter Volume and Impulsivity in Young Adults With Internet Gaming Disorder. Addict Biol 23(5): 1160-1167.

61. Wang H, Jin C, Yuan K, Shakir TM, Mao C, et al. (2015) The Alteration of Gray Matter Volume and Cognitive Control in Adolescents with Internet Gaming Disorder. Front Behav Neurosci 9: 64.

62. Park J, Sung JY, Kim DK, Kong ID, Hughes TL, et al. (2018) Genetic Association of Human Corticotropin-Releasing Hormone Receptor 1 (CRHR1) With Internet Gaming Addiction in Korean Male Adolescents. BMC Psychiatry 18(1): 396.

63. Kim N, Sung JY, Park JY, Kong ID, Hughes TL, et al. (2019) Association Between Internet Gaming Addiction and Leukocyte Telomere Length in Korean Male Adolescents. Soc Sci Med 222: 84- 90 .

64. Su B, Yu C, Zhang W, Su Q, Zhu J, et al. (2018) Father-Child Longitudinal Relationship: Parental Monitoring and Internet Gaming Disorder in Chinese Adolescents. Front Psychol 9: 95.

65. Gonzalez-Bueso V, Santamaria JJ, Fernandez D, Merino L, Montero E, et al. (2018) Internet Gaming Disorder in Adolescents: Personality, Psychopathology and Evaluation of a Psychological Intervention Combined With Parent Psychoeducation. Front Psychol 9: 787.

66. Shin YB, Kim JJ, Kim MK, Kyeong, S, Jung YH, et al. (2018) Development of an Effective Virtual eEvironment in Eliciting
Craving in Adolescents and Young Adults with Internet Gaming Disorder. PLoS One 13(4): e0195677.

67. Chaput JP, Tremblay A, Pereira B, Boirie Y, Duclos M, et al. (2016) Food Intake Response to Exercise and Active Video Gaming in Adolescents: Effect of Weight Status. Br J Nutr 115: 547-553. 
Du X, Liu L, Yang Y, Qi X, Gao P, et al. (2017) Diffusion Tensor Imaging of the Structural Integrity of White Matter Correlates With Impulsivity in Adolescents With Internet Gaming Disorder. Brain Behav 7(8): e00753.

69. Kim E, Yim HW, Jeong H, Jo SJ, Lee HK, et al. (2018) The Association Between Aggression and Risk of Internet Gaming Disorder in Korean Adolescents: The Mediation Effect of FatherAdolescent Communication Style. Epidemiol Health 40: e2018039.

70. 